\title{
Book Review: Turley, S. Justiniana Prima. An Underestimated Aspect of Justinian's Church Policy [Text]. - Krakow : Jagiellonian University Press, 2017. - 244 p. - (Jagiellonian Studies in History ; vol. 7)
}

Vadim V. Serov

Altay Institute of Economics, Barnaul, Russian Federation

\section{Yuriy A. Kreydun}

Barnaul Theological College, Barnaul, Russian Federation

\begin{abstract}
The authors of the review identify strengths and weaknesses of the Stanislav Turley's monograph dedicated to the phenomenon of the Early Byzantine city, which was named Justiniana Prima in honor of Justinian the First and his ecclesiastical construction.

Key words: Justiniana Prima, episcopate, Justinian I's church policy, Balkans, Illyricum.

Citation. Serov V.V., Kreydun Yu.A. Book Review: Turlej, S. Justiniana Prima. An Underestimated Aspect of Justinian's Church Policy [Text]. - Krakow : Jagiellonian University Press, 2017. - 244 p. - (Jagiellonian Studies in History ; vol. 7). Vestnik Volgogradskogo gosudarstvennogo universiteta. Seriya 4, Istoriya. Regionovedenie. Mezhdunarodnye otnosheniya [Science Journal of Volgograd State University. History. Area Studies. International Relations], 2018, vol. 23, no. 5, pp. 257-265. (in Russian). DOI: https://doi.org/10.15688/jvolsu4.2018.5.24
\end{abstract}

Рец. на кн.: Turlej, S. Justiniana Prima. An Underestimated Aspect of Justinian's Church Policy [Text] / S. Turlej. - Krakow : Jagiellonian University Press, 2017. - 244 p. - (Jagiellonian Studies in History ; vol. 7)

\section{Вадим Валентинович Серов}

Алтайский институт экономики, г. Барнаул, Российская Федерация

\section{Юрий Александрович Крейдун}

Барнаульская духовная семинария, г. Барнаул, Российская Федерация

\footnotetext{
Аннотация. В рецензии осуществлен краткий анализ монографии Станислава Турлея, посвященной $\underset{\approx}{\infty}$ городу Юстиниана Прима, выстроенному императором Юстинианом І в честь своей малой родины в пре․․․ фектуре Иллирик, и императорской церковной политике в этом регионе. Дается обзор содержания, подчеркиваются сильные стороны работы польского византиниста и критикуются ее недочеты.

Ю.А. Крейдун осуществил общее руководство проектом публикации и научную редактуру текста. В.В. Серов сделал перевод рецензируемого издания и подготовил текст рецензии.

Ключевые слова: Юстиниана Прима, епископат, церковная политика Юстиниана, Балканы, Иллирик.

Цитирование. Серов В. В., Крейдун Ю. А. Рец. на кн.: Turlej, S. Justiniana Prima. An Underestimated Aspect of Justinian's Church Policy [Text] / S. Turlej. - Krakow : Jagiellonian University Press, 2017. - 244 p. (Jagiellonian Studies in History; vol. 7) // Вестник Волгоградского государственного университета. Серия 4, Оे История. Регионоведение. Международные отношения. - 2018. - Т. 23, № 5. - С. 257-265. - DOI: https:// doi.org/10.15688/jvolsu4.2018.5.24
} 
Рассматриваемое издание принадлежит перу польского исследователя, давно и плодотворно трудящегося на ниве византинистики в Краковском университете. Оно представляет собой перевод с польского языка на английский (осуществленный Анной Зосенко) монографии, увидевшей свет в 2011 г. и являющейся, в свою очередь, по-видимому, вторым диссертационным исследованием автора [2].

Коллега С. Турлей совершенно точно подметил и на примере новеллы 11-й полностью реализовал давно назревшую необходимость в наиболее полном источниковедческом анализе «новых конституций» императора Юстиниана Великого, которые заключают в себе огромный запас данных по истории ранней Византии, а не только по юстиниановскому римскому праву, каковое до сих пор на их основе преимущественно изучалось. Комплексное исследование законодательных памятников юстиниановской эпохи как метод не ново, однако в отношении церковных новелл Юстиниана оно столь последовательно и полно применяется впервые. Вероятно, по этой причине работа доктора С. Турлея выглядит не вполне сбалансированной как по форме, так и по содержанию и оставляет по прочтении ощущение некой незавершенности: элементы ее структуры несоразмерны друг другу по объему и не во всем полностью сопряжены в единое логическое целое, а содержание ряда разделов изобилует повторами и интересными, но не всегда обоснованными предположениями («гипотезами»). Впрочем, очень возможно, что впечатление такого рода отчасти обязано переводу на английский язык, осуществленному, очевидно, не специалистом по истории поздней античности и не передавшему авторский замысел полностью.

Структурное своеобразие рассматриваемой публикации проистекает из авторской концепции, в рамках которой оказались неразрывно связаны личные амбиции Юстиниана в сфере внутренней и внешней политики, климатические и географические особенности северных и центральных регионов Балканского полуострова, а также соотношение сил и интенций основных участников исторических событий в Восточном Средиземноморье в ранневизантийский период - папства, иллирий- ского епископата, варваров, императора и даже отдельных чиновников имперской администрации. По версии С. Турлея, которая приобретает отчетливые очертания не вдруг, а по мере знакомства с содержанием книги, создание Юстинианом города его имени символизировало специфику взаимоотношений названных политических акторов в короткий, но чрезвычайно насыщенный промежуток времени - от начала 30-х до середины 40-х гг. VI века. Выявлению этих связей служит названный автором в качестве оригинальной исследовательской методики комплексный анализ письменных источников, упоминающих Юстиниану Приму. Ведомое методом, содержание монографии распадается на шесть неравномерных по объему глав, в которых подробнейшим образом и действительно разносторонне анализируются усилия императора Юстиниана по преобразованию церковной и гражданской систем регионального управления в связи с преимущественно внешними вызовами.

Вводный раздел издания (р. 9-21) служит, по сути, конспектом всей книги: здесь предлагается оценка историографической ситуации вокруг феномена Юстинианы Примы (p. 10, 15-17), дается обзор и характеристика основных источников (р. 11-12), а также формулируется исследовательская проблема, центральным местом которой является роль, которая отводилась Юстинианом обновленному им месту его рождения в системе государственного и церковного управления (р. 14). Необычная для традиционной историографии Юстинианы Примы постановка проблемы разрывает узкий круг сложившихся за десятилетия немногих крупных направлений изучения этого города и приводит автора к осознанию возможности ставить и разрешать огромное количество вопросов о действительном положении дел на Балканах в связи с появлением Юстинианы Примы, например о действительном статусе церкви этого города в балканской церковной иерархии, о действительном отношении к нему Юстиниана и о реальном административном и политическом эффекте, который произвела эта новая административно-территориальная единица в тогдашнем средиземноморском мире. Здесь же фактически заявляется и цель предпринятого 
коллегой С. Турлеем исследования - реконструкция Юстинианы Примы как городского центра от момента принятия решения о его строительстве до последнего упоминания его в нарративных источниках.

Осуществление намеченного таким образом плана С. Турлей начинает с первой гла$b b l$, полностью отданной под историографический обзор (р. 23-46). Правомерность выделения историографического анализа в особый раздел не вызывает сомнения, поскольку литература о Юстиниане Приме огромна. Добротный, обстоятельный обзор основной литературы включает практически все известные к настоящему времени значимые публикации, увидевшие свет за последние полторы сотни лет; при этом имеются ссылки и на более старые работы, в которых содержатся упоминания проблем, затронутых в рассматриваемом издании (например, p. 23). Список использованных российских публикаций также можно было бы считать вполне исчерпывающим, если бы в него была включена монография Федора Курганова, имеющая значение для характеристики одного из традиционных историографических направлений [1, c. 271-272, 580-592]. Примененный коллегой С. Турлеем и в отношении анализа историографии комплексный подход позволил ему выяснить, что за более чем столетие изучения феномена Юстинианы Примы сформировалось несколько «центров притяжения» исследовательского внимания, которые и составляют основу современной проблематики. Это, во-первых, «правовой статус церкви Иллирика» и его изменение на протяжении исторического времени от поздней Античности до 1767 г. - года ликвидации патриархии в Охриде (р. 24); во-вторых, реальное историческое место расположения Юстинианы Примы (р. 26); и, в-третьих, развитие системы управления (как гражданского, так и церковного) в восточной части Балканского полуострова на фоне сложной международной обстановки вокруг Иллирика в IV-VI вв. (р. 28-29). Критическая оценка известных публикаций по теме Юстинианы Примы и выявление затронутой в них проблематики завершается констатацией нелицеприятного факта нерешенности ни одного из значимых вопросов и логически вытекающим из нее выводом о необхо- димости переосмысления имеющихся научных достижений и создания многоплановой картины исторического развития того городского центра, который именуется в историографии Юстинианой Примой, вместе с относящейся к нему («подчиненной») территорией.

Реализация намеченного плана начинается коллегой С. Турлеем издалека, с комплексного анализа новелл 11 и 131, посвященных Юстиниане Приме (глава вторая, р. 4786). Рассматривая с разных сторон содержание и историю создания новеллы 11, автор выходит на множество абсолютно новых для историографии вопросов и тем. Одна из них, весьма важная для оценки степени правдивости сведений, содержащихся в новелле 11, текстологическая проблема, которая предполагает, кроме прочего, характеристику оригинальности текста этой конституции (р. 47-48). Обратив внимание на неоднородность документа, автор поделил известный текст новеллы на пять частей, изменив тем самым существующее в стереотипном издании Шелла-Кролла семичастное деление на том основании, что составитель конституции заложил в ее содержание именно пять основных сюжетов (р. 50). И действительно, можно согласиться с коллегой в том, что первая часть этой новеллы посвящена преимущественно организации новой административной единицы - apхиепископства Юстинианы Примы (р. 50-51); вторую часть законодатель уделил истории префектуры Иллирик (р. 52-55); третья часть включает описание прерогатив вновь назначенного архиепископа (р. 55-56); в части четвертой император переключается на вопросы, связанные с городом Аквис (р. 56); а последняя часть новеллы 11 явно предназначалась для того, чтобы подчеркнуть экзимированный статус церкви Юстинианы Примы в церковной организации Иллирика (р. 56-57). Структурируя таким образом анализируемый документ, С. Турлей осуществил заявленный им метод детального анализа источниковых данных. Каждый из вновь выделенных фрагментов он рассмотрел по отдельности. При этом действительно детального (в прямом смысле этого слова) анализа не получилось, поскольку для осуществления такового автору необходимо было воспользоваться методикой, уже апробированной германскими источнико- 
ведами и предполагающей построчный анализ текста. Анализ отдельных фрагментов у С. Турлея с неизбежностью оказывается разбавленным пересказом сведений источника, а равно и многочисленными предположениями по поводу обстоятельств написания новеллы 11 (пример - сюжет о фразах условно-императивного свойства в тексте новеллы, р. 55). Впрочем, в этом разделе исследования есть и интересные научные догадки, например о том, что Юстиниана Прима не располагалась в провинции Внутренняя Дакия, как считали многие (р. 54). Общим итогом данной главы явилось формулирование не новых, но впервые отчетливо выделенных и требующих дополнительного изучения вопросов: о прерогативах архиепископа Юстинианы Примы, о резиденции префекта Иллирика и о военно-политической ситуации в северо-западной части Балканского полуострова в VI веке. Решение последнего из названных вопросов в книге откладывается; первые, как более простые и ясные, начинают разрешаться здесь же (р. 56, 58-61). В рамках одного из них С. Турлей приходит к небезынтересному выводу о том, что архиепископа Юстинианы Примы нельзя приравнивать по статусу к митрополитам, что его положение в церковной администрации напоминало положение архиепископа Константинополя, не имевшего в непосредственном подчинении диоцезов и провинций, и, пожалуй, было даже лучше того, приближаясь по уникальности к положению церкви Кипра, которая не подпадала под власть ни одного из патриархов.

Проблема определения географического места резиденции префекта претория Иллирика в правление Юстиниана видится автору рассматриваемой монографии в том, что статус префекта в новелле не оформлен столь же несомненно, что и статус архиепископа (p. 64). Император будто бы не мог четко определить для себя самого, где же будет располагаться резиденция префекта с 535 г., хотя текст новеллы 11 недвусмысленно указывает именно на Юстиниану Приму: «Поэтому, когда в настоящее время <благодаря> Богутворцу наше государство увеличилось... мы посчитали необходимым расположить саму славнейшую префектуру, которая была <когда-то> учреждена в Паннонии, близ Панно- нии - на нашей счастливейшей родине...» (Nov. Just. XI.2). При этом вывод автора о том, что архиепископство Юстинианы Примы приобретало административную автономию, автоматически означает, что в Фессалонике оставался полноправный архиепископ Иллирика, вместе с которым по обычаю, узаконенному новеллой 11 , находился и префект претория Иллирика. В книге коллеги С. Турлея данное вполне логическое заключение затемнено вербальными конструкциями, цель которых, вероятно, состоит в том, чтобы убедить читателя в непоследовательности императорских решений по реформированию гражданской и церковной администрации Иллирика (р. 71).

Попытка обратиться к оценке данных новеллы 11 сквозь призму правовых норм первой трети VI в. (р. 72 сл.) выводит автора на необычайно сложные в теоретическом плане проблемы: каков должен быть статус города в системе управления для того, чтобы его церковь получила независимость и свою собственную провинцию, и каков должен быть порядок действий правителя, чтобы они не выходили за рамки государственного законодательства? С. Турлей их не решает, поскольку, по его мнению, в новелле 11 нет соответствующих данных, что является явным упущением императора, инициировавшего значительные административно-политические преобразования, но не обеспечившего их достаточным правовым сопровождением (р. 73). Этот вывод, при всей его мимолетности и неоднозначности, играет в книге о Юстиниане Приме заметную роль, так как поднимает старую медиевистскую тему цезарепапизма, которая в упрощенном виде формулируется в виде сакраментального вопроса о властных устремлениях и политических возможностях императора по отношению к церкви. Принципиальное решение проблемы цезарепапизма применительно к эпохе Юстиниана, конкретно - к 535 г., способно дать ответ и на многие другие вопросы, поставленные в рецензируемой работе, например на вопрос об умолчаниях в новелле 11, допущенных законодателем или позднейшими составителями сборника «новых конституций». Если принять цезарепапизм Юстиниана I за реальность и даже за принцип деятельности императора, решившего усовершенствовать вертикаль власти, на 
которую должны были, по его убеждению, быть нанизаны и государственная администрация, и церковь, и рудименты общественных учреждений, то тогда следует признать, что текст новеллы 11, незавершенный с точки зрения классического римского юриста, в действительности вполне закончен по смыслу, который в нее заложен, а именно: Юстиниану в 535 г. угодно было возвеличить свой родной поселок и заодно с этим показать, кто на Балканах главный. При подобном подходе к политике детали оформления документов не столь уж важны. Значение имеет лишь главная мысль, которая и высказывается в новелле предельно отчетливо. Приблизительно о том же говорит и коллега С. Турлей (р. 7677), одновременно пытаясь выявлять в новелле 11 родовые признаки источников классического римского права и при этом искренне недоумевая по поводу неполноты и неравномерной плотности текста источника (р. 77-78).

Замечателен в данной связи параграф второй главы (р. 78-81), в котором рассматривается предполагаемая бюрократическая процедура подготовки конституции к опубликованию и, таким образом, делается попытка выявить формальные основания содержательных огрехов в ней. С точки зрения процедуры в публикуемых новеллах не должно было быть недостатков, так как в Поздней Римской империи любой законопроект проходил многоэтапный процесс проверки и редактирования. Поэтому наиболее рациональным предположением о том, почему текст новеллы 11 оказался столь несовершенным, следует признать замечание С. Турлея об «инструментальном» порядке рассмотрения данного законопроекта (р. 79), или попросту о неприменении в конкретном случае традиционной процедуры продвижения закона от проекта к обнародованию. В результате внедрения в законотворчество такой автократически усеченной процедуры император Юстиниан получал желаемый текст закона, лишенный ненужных правоведческих ссылок и предполагавшихся, но нежелательных ему реверансов в сторону церковной иерархии. Последний параграф главы, вместивший в себя анализ новеллы 131 (p. 81-85), целиком подтверждает сказанное. В этой конституции, датируемой 545 г., Юстиниан несколько отступил от собственных политических амбиций, декларированных в новелле 11, и сделал это не из любви к кафолической церкви и не из уважения к папе Вигилию, возведенному на папский престол им самим, а в связи с неблагоприятными внешними обстоятельствами, которыми на сей раз воспользовались уже церковники.

В целом выводом ко второй главе могла бы быть новая констатация известного факта автократичности внутренней и внешней политики Юстиниана I, проявившейся и в отношении церкви. Однако коллега С. Турлей, избегающий выводов в конце глав, предоставляет читателю формулировать общий вывод в разделах самому.

В следующей, третьей главе (р. 87$124)$ С. Турлей обращается к другому источнику сведений о Юстиниане Приме и имперской церковной политике на Балканах - произведению «О постройках» Прокопия Кесарийского, соответствующий фрагмент которого анализируется с применением сравнительного метода. Для сравнения используются данные новеллы 11 и сведения о других городах из того же труда Прокопия.

В главе также уточняется структура и объем Прокопиева сообщения о Юстиниане Приме (р. 92-93) и получают дальнейшее развитие некоторые темы, касающиеся не столько собственно Юстинианы Примы, сколько проблем, связанных с авторством и содержанием «Построек»: о жанровой принадлежности и датировке этого произведения (p. 90-91), о «дарданском» происхождении Юстиниана как литературном приеме Прокопия (р. 95-96), вообще о писательском таланте автора «Построек». Столь глубокое и извилистое исследование Прокопиева сообщения о «родной земле императора» привело коллегу С. Турлея к нескольким интересным и оригинальным наблюдениям. Как и следовало ожидать, панегирическая составляющая «Построек» проявилась во фрагменте о родине Юстиниана в максимальной степени; Прокопий счел необходимым не только уделить описанию Юстинианы Примы особое место в IV книге своего трактата (р. 105-106), но и наделил этот городок такими свойствами, на которые тот в реальности мог лишь надеяться, к примеру статусом митрополии (р. 108118), а также комплексом публичных соору- 
жений, являвшимся в античности неотъемлемым признаком процветающего полиса. Впрочем, этот последний сюжет не удостоился в главе должного анализа, в частности, в нем отсутствует сравнение данных Прокопия с археологическими находками с наиболее вероятного в настоящее время места расположения Юстинианы Примы в Царичин Граде. Коллега С. Турлей, по-видимому, отложил данное исследование в связи с тем, что не разделяет уверенности большинства ученых в подобной географической идентификации Юстинианы Примы, которая, по его мнению, могла располагаться не на месте одного из названных Прокопием Кесарийским поселков (Бедериана и Таурезий), а рядом с ними, так что имеющиеся археологические открытия недостаточны (р. 124). Отсюда и обоснованный вывод о том, что сообщение Прокопия Кесарийского о Юстиниане Приме представляется в большей степени искусственной конструкцией, нежели описанием исторической реальности.

Небольшая четвертая глава (р. 125$133)$ посвящена важнейшему, по мнению автора монографии, сюжету о городке Аквис в новелле 11. Данные о нем являются отправной точкой для аналитического рассмотрения того фрагмента «Построек» Прокопия, который повествует о местах, упоминаемых в новелле, включая Аквис. С. Турлей предпринял усилия по аккумулированию максимально полной информации об этом городе. Она оказалась небольшой по объему и противоречивой по смыслу, так что вместо ясного представления об Аквисе как об одном из ранневизантийских населенных пунктов придунайского региона автору удалось сформулировать несколько зыбких предположений о его месте в системе государственной и церковной администрации на Балканах в VI веке. Попытка сопоставить соответствующие данные новеллы 11 и «Построек» лишь усилила нечеткость общей характеристики Аквиса, и единственным установленным в результате проделанного исследования фактом можно признать только особое отношение к нему императора Юстиниана, который преследовал на севере Балканского полуострова цель усиления византийского военного и религиозного присутствия и выбрал Аквис в качестве одного из опорных пунктов для ее осуществления.
В главе пятой, которая повествует «об обстоятельствах, сопутствующих созданию архиепископства Юстинианы Примы» (р. 135192), развиваются тезисы, сформулированные в предыдущих разделах книги и касающиеся в основном оценки современной городу политической ситуации в префектуре Иллирик (ср., например: р. 38 , п. 76 ; р. 68 , п. 79, 80; p. 69, n. 81 ; p. 74, n. 92; etc.). В начале главы значительное место уделено рассмотрению самого историко-географического феномена под названием «Иллирик» (р. 136-139), в результате которого следует весьма типичное для всех разделов книги С. Турлея высказывание о невозможности сформулировать определенный вывод по рассмотренной проблеме, в данном случае - о невозможности точной географической дефиниции позднеантичного Иллирика и, как следствие, о нежелательности использования данного понятия при анализе соответствующих конкретно-исторических объектов (р. 139).

Далее географическая акцентуация аналитического дискурса сменяется политикоадминистративной (р. 139-140, где повторяется сделанное ранее предположение о времени создания в империи префектуры Иллирик), а затем и преимущественно политической. На обширном материале разнообразных событий IV-VI вв., обступавших иллирикские церкви, рассматривается наиболее внимательно папское влияние в западно-балканском регионе, выражением которого в книге признается викариат с центром в Фессалонике (р. 140-169). В связи с этим автор стремится ответить на поставленный им самим вопрос об истинных причинах предпринятых императором Юстинианом значительных преобразований в церковной административной системе не только регионального, но и экуменического уровня. Анализ разнообразных источников (включая, например, малоизвестную специалистам Collectio Thessalonicensis - p. 141142) подталкивает его к гипотезе о скрытой и тщательно маскируемой поддержке императорами - сначала Юстином I, а потом и Юстинианом I - в Иллирике сил, которые выступали против политического присутствия здесь папства. Логика рассуждения коллеги С. Турлея приводит к предполагаемому как очевидный, но не высказанному на страницах 
рассматриваемой монографии выводу о том, что император Юстиниан, фактически одобривший действия противника римского папы фессалоникского архиепископа - и тем самым добившийся дискредитации существовавшей церковной административной структуры под названием «папский викариат в Фессалонике», по сути развязал себе руки для реформирования иллирикской церкви под предлогом наведения в ней системного порядка и посредством новеллы 11 в 535 г. передал непосредственное распоряжение церковными делами в Иллирике самому себе, оттеснив от него папство.

Как показывает предпринятый автором анализ церковной деятельности Юстиниана в начальный период его правления (например, p. 174-178), император готовился к этой «атаке» еще в начале $30-x$ гг., несмотря на то, что формально он демонстрировал папе всяческое уважение и признавал его суверенитет в церковных делах. Юстиниан I действовал с опорой на идею о главенстве имперского (публичного) закона над всеми прочими видами нормативных актов на территории, когда-либо занятой Римским государством. Государственный приоритет не допускал и тени сомнения в политическом верховенстве официального правителя над остальными имперскими субъектами политического действия. Эта вновь затронутая здесь давняя проблема соотношения светской и церковной властей, выводящая на тему пресловутого цезарепапизма, Юстинианом была теоретически разрешена в 535 г. (например, в известном высказывании о симфонии священства и царства), причем решена не в смысле равенства доступа к управлению, а в смысле распределения сфер властного влияния: под контроль священникам передавалась сфера церковная, тогда как император автократично присвоил сферу гражданского управления и законотворчество (в том числе и по религиозной проблематике, и по вопросам церковного администрирования в части, относящейся к административно-территориальному подразделению).

С этой точки зрения действия Юстиниана по переподчинению епископов Иллирика имперским церковным властям выглядят весьма логичными. И они не являлись «неожиданным поворотом в политике» (р. 179); напротив, они стали естественным следствием завершения формирования имперской идеологии и развития постклассического и юстиниановского права. Мощная тенденция в Ранневизантийском государстве при Юстиниане I к всеобъемлющей унификации вместе с выстраиванием более жесткой, чем прежде, вертикали власти неизбежно вели и к реконкисте бывших римских владений, и к перестройке традиционных отношений с католическим клиром, включая римского епископа. Политическая судьба папства, таким образом, была предрешена; избранное для этого Юстинианом время - 535 г. - показалось ему наиболее подходящим для первых существенных шагов потому, что могущество остготов тогда заметно ослабело, папство утратило политическую опору, и контроль над церковными делами на Балканах перешел к императору и подчиненному ему константинопольскому архиепископу. Сомнения коллеги С. Турлея по поводу именно такой интерпретации событий (p. 182-183) ничем не оправданы. Более того, предпринятый им замечательный исследовательский прием - рассмотреть позицию императора Юстиниана по поводу церковной организации позднеантичного и ранневизантийского Иллирика в связи с событиями церковной истории в отвоеванной византийцами Северной Африке (р. 183) - полностью подтверждает характеристику, данную выше церковной политике Юстиниана середины 30-х гг. VI века.

В последней, шестой главе (р. 193-204), несмотря на ее название («История Юстинианы Примы после 535 г.»), в большей степени анализируются не факты существования этого города после издания новеллы 11 , а, скоpee, реакция папства на факт появления нового архиепископства и на проявление уже несомненных цезарепапистских устремлений Юстиниана I. Поведение тогдашнего римского папы Агапита было предсказуемо и соответствовало современной международной обстановке в Центральном Средиземноморье, что прекрасно подтвердил и анализ в монографии давно известного, но по-прежнему востребованного источника - письма папы Агапита императору Юстиниану (р. 193-195). В нем «папа ни на что не соглашался, ничего не решал и не обещал, но настаивал на своих 
правах...», и данную фразу С. Турлея можно признать лучшим выводом по итогам продолжительного изучения вопроса об отношении папства к феномену Юстинианы Примы (р. 194). По сути, высшее руководство христианской церкви утвердило церковно-административную реформу на Балканах, а в качестве компенсации за нанесенный ему моральный ущерб от действий императора оно получило от последнего дежурное признание своей религиозной супрематии и подтверждение готовности бороться с монофизизмом.

В шестой главе проводится также анализ сведений о соотношении прерогатив светских и церковных властей Иллирика в середине VI в. из другого, гораздо менее известного и редко используемого византинистами источника - «Жизнеописания Давида» (p. 195199). Этот датируемый началом VII в. памятник агиографии, в котором нашли отражение события более чем полувековой давности, призван, по мнению С. Турлея, символизировать историю Юстинианы Примы и упомянутых в связи с ее созданием административных институтов вплоть до 602 г., когда город был упомянут современниками в последний раз (р. 204). Анализ данных из Vita Davidi позволил автору монографии остроумно реконструировать ход событий, произошедших после опубликования новеллы 11 (р. 199). По мнению С. Турлея, назначенный в 535 г. архиепископом Юстинианы Примы Кателлиан передал основное содержание этой новеллы фессалоникскому архиепископу Аристиду, тем самым уведомив его в том, что церковная власть над Иллириком переходит от епископа Фессалоники к епископу Юстинианы Примы. Чтобы поддержать ослабевшую в результате такой передачи Фессалонику, Юстиниан закрепил за ней статус постоянной резиденции префекта претория, до того принадлежавший Сирмию, а уведомление об этом префект Иллирика получил уже напрямую от императора (р. 200).

Таково вкратце содержание основной части рецензируемой монографии. Заключение к ней коллега С. Турлей построил нетрадиционно, скомпоновав его отчасти из тех выводов, которые должны были завершать каждую из глав, но в них не попали. Таков, например, вывод об особенностях управления позднеантичной церковной организацией Ил- лирика, которые, по мнению автора работы, заключались в хитроумном, но не вполне последовательном разделении власти над церковью Иллирика между патриархией Константинополя и римским понтификатом, согласно которому фактическое управление иллирийским диоцезом находилось в руках папы, тогда как Константинополь должен был довольствоваться формальной возможностью вмешиваться в церковные дела на Балканах через посредство государственных нормативных актов, издаваемых императором (р. 207-208). Но и описывая данную конструкцию, автор вновь не говорит о том, что такое ненормальное с точки зрения императорской власти положение не могло не завершиться рано или поздно перераспределением властных полномочий в регионе в пользу наиболее мощной политической силы, так что соответствующие усилия императоров первой половины VI в. оказались закономерными и были реализованы в подходящих для этого условиях.

В целом исследование доктора Турлея следует охарактеризовать как интересное, но незавершенное начинание. Опуская вопрос о причинах увлечения коллеги С. Турлея, являющегося специалистом по международной проблематике средневизантийского периода, столь сложной темой, как политика Юстиниана I, необходимо заметить, что для всеобъемлющего ее раскрытия требуется не только диверсифицированное представление об одном из аспектов внешнеполитической деятельности имперского правительства, но и панорамное видение многих аспектов внешней и внутренней политики ранней Византии и ее связи с максимальным количеством событий, которые происходили на обширнейшей территории позднеантичного мира. Знание этой аксиомы коллега С. Турлей ясно продемонстрировал. Однако теория know how в его книге не реализовалась на практике в полной мере. Множество неизбежных при заявленном автором подходе (всесторонний анализ) сопутствующих небольших, но важных для описания общей картины тем, которые тоже должны быть раскрыты в соответствии с принципом комплексного исследования, либо остались в рецензируемой работе на стадии лишь формулирования, либо получили недостаточное освещение, завершившееся одни- 
ми предположениями. В связи с этим можно было бы надеяться на продолжение и расширение исследования, начатого столь многообещающе. Это позволило бы автору сделать его действительно комплексным и внести значительный вклад в византинистику, продвинув решение ряда вопросов. В частности, удалось бы реализовать заявленную здесь цель исследования и впервые детально рассмотреть развитие города Юстиниана Прима на основе комплекса данных всех доступных источников, включая новеллы, трактат Прокопия Кесарийского и археологические находки.

Поэтому поблагодарим коллегу С. Турлея за его прекрасный подарок - эту книгу, дающую немало практической пользы и новую пищу для размышлений, - и пожелаем ему новых успехов в исследовании юстиниановской эпохи в самой широкой трактовке этого понятия.

\section{СПИСОК ЛИТЕРАТУРЫ}

1. Курганов, Ф. Отношения между церковною и гражданскою властью в Византийской империи.
Обзор эпохи образования и окончательного установления характера взаимоотношений между церковною и гражданскою властью в Византии (325$565)$ / Ф. Курганов. - Казань : Тип. Импер. ун-та, 1880.- VI, 720, [3] c.

2. Turlej, S. Justyniana Prima. Niedoceniony aspekt polityki kościelnej Justyniana / S. Turlej. Kraków : Historia Iagellonica, 2011. - 265, [1] s. (Notos, Scripta Antiqua et Byzantina ; vol. 8).

\section{REFERENCES}

1. Kurganov F. Otnosheniya mezhdu tserkovnoyu i grazhdanskoyu vlastyu v Vizantiyskoy imperii. Obzor epokhi obrazovaniya i okonchatelnogo ustanovleniya kharaktera vzaimootnosheniy mezhdu tserkovnoyu $i$ grazhadanskoyu vlastyu v Vizantii (325-565) [Relations between Church and Civil Power in the Byzatine Empire. A Survey of the Epoch of Education and the Final Formation of the Relationship between Church and Civil Power in Byzantium (325-565)]. Kazan, Tipographiya Imperatorskogo universiteta Publ., 1880. VI, 720, [3] p. (in Russian).

2. Turlej S. Justyniana Prima. Niedoceniony aspekt polityki kościelnej Justyniana. Kraków, Historia Iagellonica, 2011. 265, [1] s. (Notos, Scripta Antiqua et Byzantina; vol. 8).

\section{Information about the Authors}

Vadim V. Serov, Doctor of Sciences (History), Associate Professor, Professor of Department of State and Law, Altay Institute of Economics - Branch of Saint Petersburg University of Management Technologies and Economics, Prosp. Lenina, 106e, 656011 Barnaul, Russian Federation, wseroff@yandex.ru, https://orcid.org/0000-0003-0348-5499

Yuriy A. Kreydun, Doctor of Arts, Vice-Rector for Education, Barnaul Theological College, Yadrintseva Lane, 66, 656008 Barnaul, Russian Federation, krey70@mail.ru, https://orcid.org/0000-00020746-8875

\section{Информация об авторах}

Вадим Валентинович Серов, доктор исторических наук, доцент, профессор кафедры государственно-правоведческих дисциплин, Алтайский институт экономики - филиал Санкт-Петербургского университета технологий управления и экономики, просп. Ленина, 106е, 656011 г. Барнаул, Российская Федерация, wseroff@yandex.ru, https://orcid.org/0000-0003-0348-5499

Юрий Александрович Крейдун, доктор искусствоведения, проректор по учебной части, Барнаульская духовная семинария, пер. Ядринцева, 66, 656008 г. Барнаул, Российская Федерация, krey70@mail.ru,https://orcid.org/0000-0002-0746-8875 